Mr. F. Y. Poynton spoke on "Applied Physics in Technical Colleges", and described the work done in the formal courses at the Northampton Polytechnic, and also in special courses of lectures and practical work which had been established from time to time to meet some particular need, instancing the course on high-vacuum work in his department, which many members of the conference had been able to visit. Dr. J. Topping, in a paper on "Research in Technical Colleges", emphasized the importance of research as a vitalizing factor in the work of a college, and mentioned the difficulties that arose in the implementation of Circular 94. At the Regent Street Polytechnic only a few of the many applicants for part-time research could at present be accepted, and the demand for higher study is being to some extent met by postgraduate lecture courses instead. The interests and ability of the staff will determine the type of research undertaken in a particular college; the problems will usually be such as require only limited space and equipment, and will be linked with the specialist courses in applied physics. It has to be considered how far the suggestion of the Percy Committee, that colleges should undertake investigations for local industrial firms, is practicable or desirable. During the discussion, Dr. J. E. Richardson said that there must be a distinction between the problems posed by industry and those selected by the colleges themselves. The first line of attack is for the colleges to choose work which will be of industrial significance. Dr. Lowery suggested that the technical colleges will only attain their full status when industry, and the governing bodies of the colleges themselves, have been brought to appreciate that they are really capable of carrying out major research of a high order.

The opportunities for informal discussion between sessions were greatly appreciated, and one left with an accurate picture of the whole of the field of physics teaching that lies outside the universities, and also encouraged by the zeal with which the resources for the recruitment of the nation's scientific man-power are being marshalled.

G. R. NOAKES

Clarke, N., J. Sci. Instr., 28, 50 (1949).

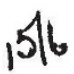

\section{CLIMATIC RACES OF ACHILLEA}

$\mathrm{P}$

ART 3 of the "Experimental Studies in the Nature of Species" (t) " wenvironmental Responses of Climatic Race of Achillea", by J. Clausen, D. D. Keck apd. $W_{H}$. Hiesey, Carnegie Institute of Waghington Publication 581, 1948) is a worthy meftur of a remarkable series of researches which is rapha casting a flood of light on the dynamics of evolutionary processes. Starting with Turesson's concepts of ecotypes, etc., and from his simple technical approach to the detection of physiological subdivisions within the lowest taxonomic units, the effective collaboration of three very different members of a powerful team, amplified by the natural resources of California, have developed a series of refined techniques for revealing evolution in action in a way which has not been attempted elsewhere.

As in Turesson's original investigations the first step in these studies is always the close comparison of samples of different populations of a species, derived from different ecological or climatic habitats, under the uniform conditions of an experimental garden by means of which genetically determined differences can be separated out from temporary modifications imposed from without. Achillea is shown to be a very favourable experimental object for this purpose owing to its exceptionally wide geographical and climatic range, as well as to its ease of cultivation and prolific growth. By the skilful application of statistical methods to an enormous wealth of material the existence of very many significantly different types of populations is demon. strated both on a transect across California from the coast inland over the coastal ranges and Sierra Nevada, which lays the emphasis on altitude, and also on a latitudinal transect up the American continent from California to Alaska and in a limited amount of material from Europe. Local populations are shown to be mixtures of biotypes, the composition of the mixture varying somewhat in neighbouring populations within the same climatic belt. A distinct zonation of biotypes nevertheless always occurs in passing from one climatic belt to the next; this makes it possible to distinguish climatic races. A few of the characters by which biotypes are distinguished are morphological (height, leaf textures, etc.); but far more commonly they are physiological, involving characters such as growth-rate, length and timing of dormant periods, date and duration of flowering, frost or drought sensitivity, etc.

The next step in the inquiry here, as in the previous studies, is the close comparison of clones of selected biotypes in each of three transplant stations (Stanford, Mather and Timberline), representing the range of available altitudes in the same latitudinal belt. From this the adaptive significance or otherwise of the observed differences can be tested. In the event it is very clearly shown that an unmistakable equilibrium exists between habitat and population. Many compromises are tolerated in individual cases in which lack of fitness in one character may be compensated by the possession of some other ; an example quoted is the counteraction of the ill-effects of frost sensitivity in an alpine habitat by means of precocious fruiting. On balance, however, each population is found to be better suited to its own environment than to others, a condition which seems to point unmistak. ably to natural selection acting in a strictly Dar. winian sense.

A third technique which is introduced here for the first time is the further analysis of the individual physical and physiological factors involved in the selection process by the comparative study of clonal material of selected biotypes under exactly controlled greenhouse conditions. At different temperatures, light intensities and lengths of day, clear-cut differences of reaction could be uncovered between selected biotypes from which some insight could be gained into the significant physiological factors (minimum light requirements, rates of photosynthesis, etc.) involved in the climatic reactions. These have not yet been further analysed to reveal their genetical make-up; but if such analysis can be provided Achillea is likely to become the best example yet investigated for revealing in detail the mode of operation of climate in inducing subspecific differentiation in a plastic species.

It is the authors' opinion that the development of many climatic races is necessary to the attainment of a wide geographical range. This is certainly often the case, though whether Achillea is an extreme example is not quite so clear. It is likewise often the case that the attainment of a wide geographical range 
precedes the splitting up of a species into others, and so this extent we may feel that we are witnessing in Achillea not micro-evolution only (to use the name coined by Goldschmidt) but a phase of macroevolution also. That it is a phase only and not necessarily the whole story of macro-evolution the authors themselves would probably be the first to admit. The facts so far ascertained for Achillea are, however, a salutary reminder that evolutionary trends are not wholly directed by factors internal to the organism, as some evolutionists, in reaction against simple Darwinism, have recently tended to think, and for this purpose alone, therefore, this work merits close attention.

I. MANTON

$H=$

\section{TREASURY GRANTS FOR SCIENCE AND RESEARCH IN GREAT BRITAIN}

A MONG the items of interest to scientific workers $A$ in the Civil Estimates for 1949-50, Class I, Central Governf $£ 32,625$ fon the Central Economic Planning Staff, the staff of whish is reduced from 28 to 24 , and $£ 23,787$ for the Economic Information Unit, the staff of which is increased from 13 to 22 . The Organisation and Methods Division of the Treasury has also been expanded with a staff of 79 as against 57 in the previous year and with a vote of $£ 71,706$ in place of $\{51,733$.

For the Government Chemist $£ 188,061$ is required, an increase of $£ 16,333$, while the estimate for the Office of the Lord President of the Council is practically unchanged at $\$ 19,200$, in spite of an increase of 4 in the scientific staff. The Estimates for Class IV (Education and Broadcasting) include $£ 144,091$ for the Science Museum as against $£ 132,443$ in $1948-49$, $\{275,712$ for the British Museum, a net decrease of $£ 8,215, £ 215,315$ for the British Museum (Natural History), a net increase of $£ 17,666$, and $£ 14,150,000$ for broadcasting, a net increase of $£ 450,000$. Estimates of $£ 3,370,868$ for science and the arts include $£ 43,500$ for the Royal Society ( $£ 20,000$ for scientific investigations and $£ 17,250$ for scientific publications), $£ 40,500$ for the National Library and $£ 41,000$ for the National Museum of Wales, $£ 22,500$ for the National Central Library, $\mathfrak{1 1 , 6 1 8 , 0 0 0}$ for the Medical Research Council, of which $£ 369,000$, or the bulk of the increase of $£ 483,000$, is for the erection and structural adaptation of buildings and the purchase of special equipment, including a cyclotron, $£ 777,000$ for the Agricultural Research Council (an increase of $£ 327,000), £ 100,000$ for Nature Conservancy, $£ 575,000$ for the Arts Council of Great Britain and $£ 46,000$ for the British Film Institute. With $£ 2,000$ for the Royal Society of Edinburgh and $£ 3,000$ for the Solar Physics Observatory the estimates for research and development under Class IV, Science and the Arts section, amount to $£ 2,543,500$.

An appendix to the Estimates sets forth the other amounts provided for research and development in the Estimates for $1949-50$ and totalling $£ 96,072,533$. This includes $£ 6,632,000$ for scientific services in the Navy Estimates, as well as $£ 2,758,000$ under shipbuilding repairs, maintenance, etc., and $£ 481,000$ under Works, Building and Repairs at Home and Abroad. Under Class II, there are $£ 35,765$ for
Commonwealth Economic and Research Services, $£ 10,000$ for the National Institute of Oceanography, and $£ 950,000$ for Development and Welfare (Colonies, etc.) Research Schemes. Research and testing under the Ministry of Fuel and Power are estimated at $£ 226,600$, while Class VI also includes $£ 1,240,970$ for agricultural, fishery and shell-fish research, $£ 139,300$ for forestry research, and $£ 424,807$ for the Development Fund. For the Department of Scientific and Industrial Research the net amount is $f 4,199,625$, and for agricultural research under the Department of Agriculture for Scotland, $£ 500,021$. Under the Ministry of Works, the estimate for scientific and research establishments, etc., amounts to $£ 918,685$, and miscellaneous items bring an estimate of $£ 54,800,000$ for research and development under the Ministry of Supply to a total of $£ 74,473,000$.

For the Universities and Colleges, etc., of Great Britain, $£ 17,671,500$, an increase of $£ 5,168,500$, is provided, including a loan of $£ 75,000$ for housing accommodation for staff and $£ 32,000$ for postgraduate studentships in Oriental, Slavonic, East European and African studies. Non-recurrent grants represent $£ 4,750,000$, and of the remainder $£ 8,482,853$ is for English Universities, $£ 504,200$ for Wales and $£ 1,538,537$ for Scottish Universities. In addition to those grants made on the recommendation of the University Grants Committee, there are a number of grants for specific purposes made to individual universities by different Departments or bodies, and these are given in an appended schedule.

\section{FORTHCOMING EVENTS}

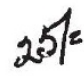

(Meeting marked with an asterisk * is open to the public)

\section{Monday, April II}

MANCHESTRR LTTERART AND PHILOSOPHICAL SOCIETY (in the Reynolds Hall, ollege of Technology, Manchester), at 5.30 p.m.Mr. R. F T T. T.

Ro SAx GEOORAPHICAL SOCIETY (at Kensington Gore, London, S.W.7) at 5.30 p.m. "North-West Tran To-day" (Kodachrome films with commentary by Sir Clarmont Skrine).

NORTH-EAST COAST INSTITUTTON OF ENGINEERS AND SHIPBUILDERS (in the Mining Institute, Newcastle-upon-Tyne), at 6 p.m.-Mr. W. Muckle : "Experiments on a Light Alloy Model Superstructure"."

INSTITUTION OF ELECTRICAL ENGINGHRS, EDUCATION DISCUSSION CIROLE (at Savoy Place, Victoria Embankment, London, w.C.2), at 6 p.m.-Discussion on "The Scheme for the Interchange of Information on Electrical Encineering Laboratory Practice" (to be opened by Dr. F. Bradshaw) and "Transient Display Apparatus" (to be opened by Mr. A. C. Normington).

\section{Tuesday, April 12}

ROYAL SOCIETY OF ARTS, DOMINIONS AND COLONIES SECTION (at John Adam Street, Adelphi, London, W.C.2), at 2.30 p.m.-Sir Frank Stockdale, G.C.M.G.: "Colonial Development".

Societr of Chemian Industry, Plastics Grodp (at the Royal Society of Tropical Medicine, Manson House, 26 Portland Place, London, W.1), at 2.30 p.m.-Dr. W. C. Fergusson: "Polytetrafluorethylene",

ZoOLOGICAI SoOIETY of LONDON (at the Zoological Gardens, Regent's Park, London, N.W.8), at 5 p.m.--Scientifle Papers.

INSTITUTION OP ELECTRIOAL ENGINEERS, RADIO SECTION (at Savoy Place, Victoria Embankment, London, W.C.2), at 5.30 p.m.-Dr. R. H. Barfield: "Radio-Frequency Heating".

Institution of MECHanical EngineERs (at Storey's Gate, St. James's Park, London S.W.1), at 6 p.m-Mr. H. R. Mills and Mr. James's Park, London, S.W.1), at 6 p.m.-Mr. H. R. Mills
R. J. Love : "The Fatigue Strength of Cast Crankshafts".

Manchester Grographicax Society (in the Geographical Hall, St. Mary's Parsonage, Manchester), at 6.30 p.m.-Mrs. E. D. Pugh "In and Around Madras".

Sheffield Metaludraical Association (at 198 West Street, Sheffield), at 7 p.m.-Dr. G. R. Davies: "Chromatography".

SOCIETY OF INSTRUMENT TECHNOLOGY, NORTH-WEST SRCTION (at the College of Technology, Manchester), at 7.30 p.m.-Mr. D. O. Walter: "Some Metals and Alloys for the Instrument Designer". 